\title{
A Review between Climate Smart Agriculture Technology Objectives' Synergies and Tradeoffs
}

\author{
Petros Chavula \\ ${ }^{1}$ Africa Center of Excellence for Climate Smart Agriculture and Biodiversity Conservation and Management, P. O. Box 138, Ha- \\ ramaya, Oromia, Ethiopia. \\ ${ }^{2}$ Department of Climate-Smart Agriculture, Haramaya University, Haramaya, Oromia, Ethiopia.
}

How to cite this paper: Petros Chavula (2021) A Review between Climate Smart Agriculture Technology Objectives' Synergies and Tradeoffs. International Journal of Food Science and Agriculture, 5(4), 748-753.

DOI: $10.26855 /$ ijfsa.2021.12.023

Received: November 2, 2021

Accepted: November 26, 2021

Published: December 20, 2021

*Corresponding author: Petros Chavula, Africa Center of Excellence for Climate Smart Agriculture and Biodiversity Conservation and Management, P. O. Box 138, Haramaya, Oromia, Ethiopia; Department of Climate-Smart Agriculture, Haramaya University, Haramaya, Oromia, Ethiopia.

Email: petroschavula2@gmail.com

\begin{abstract}
Climate variability and extremes are now a part of everyday life around the planet. Climate change has a significant impact on the poor and vulnerable in various parts of the world. Climate variability and change have exacerbated the miseries of the impoverished in various parts of the world, including the well-to-do. As a result, several stakeholders around the world have created and executed climate change adaptation and mitigation programs. These projects and/or programs seek to mitigate the effects of climate change on the environment, specifically on humans. Projects have mostly targeted the least developed countries (LDCs) and disadvantaged households who are affected by climate change variability (smallholder farmers). Farmers in smallholdings have been encouraged to implement these projects on their land. Furthermore, some governments have implemented policies aimed at accomplishing the aims of climate smart agriculture. There are synergies and trade-offs between these actions for accomplishing climate smart agriculture's goals (e.g. rotational grazing system for cattle, agroforestry adoption, integrated-cattle soybean production, and biotechnology promotion has showed higher food production and lower greenhouse gas emission). Lack of interest, inadequate policies, and a scarcity of land for rotation grazing, reduced productivity, and worse financial returns are only a few of the trade-offs of these interventions. As a result, via the development of appropriate strategies and regulations, climate smart agriculture aims to eliminate trade-offs and increase synergies. For higher production and guaranteed sustainability, these policies should attempt to promote synergies in crop production, animal production systems, forests, fisheries, and aquaculture. Climate-smart agriculture is not a brand-new farming method or collection of activities.
\end{abstract}

\section{Keywords}

Trade-Offs, Synergies, Adoption, Climate Change, Agriculture, Greenhouse Gases, Smallholder Farmers, Biotechnology and Tenure

\section{Introduction}

The Fourth Report of the Intergovernmental Panel on Climate Change (IPCC) (2007) dispels any doubts regarding climate change and provides precise estimates for the twenty-first century, demonstrating that global warming will continue to rise [1, 2]. As a result, global warming's effects, such as disruptions in food and water systems, will have a negative impact on development and livelihoods, and will very certainly add to the obstacles already posed by climate change in eradicating poverty [3]. This is anticipated to have an impact on rural impoverished communities' social, cultural, and economic growth, as well as agricultural output, especially in Sub-Saharan Africa [4-6]. 
According to [7], global warming of the atmosphere and oceans, changes in rainfall patterns, and an increase in the frequency of extreme weather events have already been seen. Oceans and seas are becoming more saline and acidic, influencing aquatic species' physiological and behavioral habits as well as productivity, habitats, and migration patterns [8]. The rising sea level, combined with stronger storms, has posed a serious threat to coastal communities and ecosystems [9]. Human activities are threatening to destroy the majority of the world in the coming centuries. Increased temperatures are causing certain inland water bodies, such as lakes, rivers, and streams, to dry up [10]. Other locations, on the other hand, are periodically subjected to destructive flooding. The poorest communities in the poorest countries are frequently the most vulnerable to these shifts [11].

Over the years, scientists and multilateral organizations have debated the best strategies to adapt to and mitigate the effects/impacts of climate change. What was more obviously emerging from the arguments was how disadvantaged groups may be aided [12]. As a result, climate-smart agriculture emerged as a path to future agriculture rather than a solution. Climate-smart agriculture emerged as a framework in 2010, propelled by the international community, as a notion for developing and implementing agricultural systems that promote climate adaptation and mitigation at the same time [13, 14]. Climate-smart agriculture, according to [15] and [16], comprises methods that are already in use, but it also emphasizes the application and modification of established technologies. In this vein, researchers must document ways for farmers, industry, consumers, and government to move toward, expand, or shift the "space" that allows multiple benefits from sustainable farming practices to be realized [15], as well as envision landscapes that are resilient to future change $[17,18]$.

In general, examining synergies and trade-offs between climate-smart agriculture goals is a critical step in developing solutions to sustainability problems [17-19]. The assessment, according to [17], can be accomplished by examining how alternative combinations of technical measures and behavioral modifications can achieve many long-term goals.

Conferring to [12], Climate Smart Agriculture (CSA) aims to tackle three main objectives: sustainably increasing agricultural productivity and incomes; adapting and building resilience to climate change; and reducing and/or removing greenhouse gas emissions, where possible

\section{Literature Review}

\subsection{Future of Climate-Smart Agriculture}

Climate-smart agriculture's interventions have the potential to feed the world's growing population without causing environmental damage. According to the [12], the goal for the next 30 years and beyond is to grow more food with less environmental impact. Its goal, however, is to supply the increased need for food, fibre, and fuel while leaving a considerably smaller environmental footprint.

Climate-smart agriculture has been promoted by both industrialized and developing countries in recent years. Despite global efforts to promote climate-smart agriculture, it faces obstacles. Production, productivity, poverty reduction, and environmental sustainability are all competing concerns during this shift from traditional agricultural production to climate-smart agriculture [20, 21]. Despite these obstacles, climate-smart agriculture goals can be achieved through a variety of methods (e.g., it is well known that agriculture remains the major cause of deforestation worldwide). Agriculture is responsible for around a quarter of all annual greenhouse gas emissions (e.g. methane, and ammonia from livestock and nitrates from inorganic fertilizers) [22]. Agricultural output, particularly crops and cattle, accounts for over $70 \%$ of inland freshwater withdrawals, regardless of the season. Nonetheless, people must eat, and the majority of smallholder farmers rely on agriculture as a source of income and will continue to do so [23].

\subsection{Synergies of Climate-Smart Agriculture}

Many approaches have been proposed to adapt to changing climates in order to achieve the goals of climate-smart agriculture [24, 25]. Plant genetics improvements as adaptive measures to climate change, according to [26], include genetic modifications for drought tolerance and improved root architecture for crops [27]. Soil conservation, agronomic management (such as shifting planting dates), water technologies (irrigation and harvesting), and financial instruments are all part of this (crop and weather insurance).

Climate-smart agriculture relies heavily on biophysical and socioeconomic contexts for societies to manage farms, crops, livestock, aquaculture, and capture fisheries; climate-smart agriculture relies heavily on biophysical and socioeconomic contexts for societies to manage farms, crops, livestock, and aquaculture, as well as capture fisheries. Switching types or species, modifying cropping calendars, and nutrient management techniques like micro-dosing, mulching, or organic fertilizer application are all choices [6]. The goal is to produce a high yield.

Improved pasture and feed quality, herd management changes, and specific responses to heat stress are all options for livestock. Conjoining species and managing temperature are climate-smart options in aquaculture, whereas changing locations, quotas, and species are all significant in fisheries [28]. Diversification of production, integrated 
crop-livestock systems, agroforestry, restoring organic soils, limiting soil erosion, energy efficiency, biomass fuels, integrated pest management, and improved water resource and irrigation management are among the inclusive farm-management preferences [6, 29].

Landscape and/or ecosystem management: Climate-smart agriculture also encourages looking at agricultural systems in the context of larger landscapes and ecological systems in order to better understand the interconnections between agricultural production and ecological system services both within and outside of agro-ecological systems [30, 31]. A critical component is the function of water-resource management and land-use change in food security, adaptation, and mitigation across landscapes. Regulation and provision of ecological system functions, such as hydrology and biological variety, can result in production, adaptation, and mitigation co-benefits, especially in the soil [32, 33]. Food security, development, climate change adaption (microclimate), water management, soil protection, agrobiodiversity protection (pollinators), and succour with carbon storage and greenhouse gas emission reduction can all be benefited from multi-objective forest management [33, 34].

Increasing the adaptive ability of farmers, herders, fishermen, and foresters necessitates expanding a range of services. Climate information services, such as seasonal predictions or early-warning systems alluded by [35], [36] and [37] advising services that relate climate information to agricultural decisions, and financial services, such as credit and insurance, are all examples of these. Despite rising climate variability, social protection and new index-based weather insurance products may help smallholder farmers invest in agriculture [37].

Changes in the broader food system: Adaptation and mitigation efforts that promote food security and livelihoods are not solely focused on agricultural productivity [12, 16]. Harvesting, storage, transportation, primary and secondary processing, retail, and consumer behaviors are all critical components of the CSA-enabling and motivating ecosystem.

\subsection{Tradeoffs of Climate-Smart Agriculture}

Despite climate-smart agriculture, the method seeks to address the effects of climate alternate on agriculture manufacturing via advertising synergies to make crop and livestock systems, forestry, and fisheries, and aquaculture extra productive and extra sustainable. Below are some of the trade-offs between climate-smart agriculture objectives:

Large-scale bioenergy production brings trade-offs, such as forest or water protection [38, 39] (i.e., increases in food prices, which makes it a negative contribution to poor households). Agriculture intensification and improved fertility input efficiency, on the other hand, are not cost-effective for marginalized populations, for example, improved cultivars, improved animal breeds, and irrigation equipment [39]. Costs, in particular, are a common deterrent for smallholder farmers to embrace climate-smart agriculture practices.

Despite the fact that climate change is a global issue, most countermeasures or policy implementations are done at the national and/or even local level [39]. Similarly, specific Sustainable Development Goals (SDG) targets are established at the national level and on a national scale, and they do not apply to other countries. National policy proposals and strategies are essential within that framework for resolving sustainability issues associated with climate actions, but national research is still limited and unknown. Furthermore, most countries heavily subsidize fuel, which creates a huge disincentive for farmers to use water and energy properly [38, 40]. Moving forward, we must change this situation through strategies such as water policy, water tariffs, and reduced fuel subsidies, while also developing a reliable social safety net that will not push millions into poverty and jeopardize the country's stability [41].

When it comes to climate-smart agriculture, land use decisions and tenure systems are frequently complicated trade-offs [41-43]. Unless enabling and supporting actions are done, the latter will have an impact on the most vulnerable stakeholders. At the family level, decisions are made about which experiments to conduct, each with its own set of upfront costs and risks for farmers. This implies farmers will demand not only a variety of CSA techniques, but also CSA interventions suited to local conditions and vulnerable communities [44]. The majority of smallholder farmers are wary of taking risks by adopting new agricultural technology.

Agriculture interventions that are climate-smart are designed to mitigate the effects of climate change. These activities primarily aimed at impoverished households, particularly in LDCs [43, 45-46]. Although obtaining inputs (cost or availability) is more difficult, higher labor requirements are also more challenging (e.g., agroforestry technology installation, conservation agriculture, biotechnology cost, organic farming labour, water harvesting techniques). Climate-smart agriculture technology are likely to fail and/or be ineffective, which is a trade-off [1-2, 46]. Other factors that contribute to CSA's failure to achieve its goals include a lack of funding, poor extension services in most developing countries, a lack of patient adopters, weak institutions to enforce policies, donor dependency syndrome, a knowledge gap, and a lack of community interest, to name a few.

Furthermore, the timing of climate change mitigation and policy instrument deployment can alter the multi-sectoral impacts. According to [2] and [38] evaluated the trade-offs in meeting climate targets under five possible bioenergy and land-use strategies, finding that deforestation would be common if no complementing land policy was implemented. 


\section{Conclusion and recommendation}

Early climate action is preferred for resolving trade-offs, and near-term climate action to reduce GHG emissions is an important component because it also helps to lessen mid-term trade-offs. Agriculture is one of the most studied sectors when it comes to the effects of climate change since it is one of the most vulnerable. Climate change and unpredictability pose additional development problems, particularly in LDCs, where the bulk of the population is dependent on climate-sensitive industries, such as agricultural output. Concerns about the additional challenges that climate change poses to agricultural development in order to meet poverty reduction and food security goals have risen sharply in recent years on the international and national policy agendas, and agriculture is regarded as one of the most effective ways out of poverty.

Climate-smart agricultural technology development is a critical method for enhancing agricultural output, establishing food self-sufficiency, and alleviating poverty and food insecurity among smallholder farmers in response to this problem. Smallholder farmers' households around the world have been adopting and employing various climate-smart agricultural technology for quite some time now, albeit acceptance has not been perfect due to unforeseen hurdles.

Governments, non-governmental organizations, and other civil society organizations must intensify their efforts to promote CSA technologies among farmers across the globe. This has the potential to greatly enhance the rate of farmer adoption. This will improve not only the adoption of CSA technology, but also mitigation, resilience, and production, hence improving farmer household income. Money lending organizations should consider entering this sector to provide credit as well. Farmers who have access to credit services are thought to be more likely to adopt new agricultural technologies than those who do not.

\section{References}

[1] Intergovernmental Panel on Climate Change, “Assessing Transformation Pathways,” Clim. Chang. 2014 Mitig. Clim. Chang., pp. 413-510, 2015, doi: 10.1017/cbo9781107415416.012.

[2] M. Jarraud and A. Steiner. (2012). Summary for policymakers, vol. 9781107025066. 2012.

[3] A. Haro, A. Mendoza-Ponce, Ó. Calderón-Bustamante, J. A. Velasco, and F. Estrada. (2021). "Evaluating Risk and Possible Adaptations to Climate Change Under a Socio-Ecological System Approach,” Front. Clim., vol. 3, no. June, pp. 1-16, 2021, doi: 10.3389/fclim.2021.674693.

[4] S. M. Howden, J.-F. Soussana, F. N. Tubiello, N. Chhetri, M. Dunlop, and H. Meinke, “Adapting Agriculture to Climate Change: Preparing Austrailia,” Pnas, vol. 104, no. 50, pp. 19691-19696, 2007, [Online]. Available: https://www.pnas.org/content/pnas/104/50/19691.full.pdf.

[5] S. Asfaw and L. Lipper. (2011). "Economics of pgrfa management for adaptation to climate change: a review of selected literature,” Comm. Genet. Resour. Food Agric., no. Background Study Paper No. 60, pp. 1-25, 2011.

[6] W. E. Easterling, et al. (2007). "Food, fibre and forest products,” Clim. Chang. 2007 Impacts, Adapt. Vulnerability. Contrib. Work. Gr. II to Fourth Assess. Rep. Intergov. Panel Clim. Chang., pp. 273-313, 2007.

[7] D. Khadka and D. Pathak. (2016). "Climate change projection for the marsyangdi river basin, Nepal using statistical downscaling of GCM and its implications in geodisasters,” Geoenvironmental Disasters, vol. 3, no. 1, 2016, doi: 10.1186/s40677-016-0050-0.

[8] P. Nkala, N. Mango, M. Corbeels, G. J. Veldwisch, and J. Huising. (2011). "The conundrum of conservation agriculture and livelihoods in Southern Africa,” African J. Agric. Res., vol. 6, no. 24, pp. 5520-5528, 2011, doi: 10.5897/AJAR10.030.

[9] R. Mendelsohn. (2000). "Efficient adaptation to climate change,” Clim. Change, vol. 45, no. 3-4, pp. 583-600, 2000, doi: 10.1023/a:1005507810350.

[10] C. L. Holt. (1994). "Effectiveness of a multicultural education unit on the cultural sensitivity of undergraduate hospitality students,” Hosp. Tour. Educ., vol. 6, no. 3, pp. 75-75, 1994, doi: 10.1080/23298758.1994.10685604.

[11] R. S. J. Tol. (2008). "Why worry about climate change? A research agenda,” Environ. Values, vol. 17, no. 4, pp. 437-470, 2008, doi: 10.3197/096327108X368485.

[12] T. Status, C. Agriculture, and S. Africa. (2010). "The Status of Conservation Agriculture in Southern Africa Challenges and Opportunities for Expansion Africa’ s level of CA practice,” pp. 1-6, 2010.

[13] C. A. Harvey, et al. (2014). "Climate-Smart Landscapes : Opportunities and Challenges for Integrating Adaptation and Mitigation in Tropical Agriculture,” vol. 7, no. April, pp. 77-90, 2014, doi: 10.1111/conl.12066.

[14] B. R. Baral, T. W. Kuyper, and J. W. Van Groenigen. (2014). "Liebig's law of the minimum applied to a greenhouse gas: Alleviation of P-limitation reduces soil N2O emission,” Plant Soil, vol. 374, no. 1-2, pp. 539-548, 2014, doi: 10.1007/s11104-013-1913-8. 
[15] S. Agriculture and C. Change. (2003). “GHB-abstinens,” Lakartidningen, vol. 100, no. 46, p. 3776, 2003.

[16] S. S. Yadav, R. J. Redden, J. L. Hatfield, A. W. Ebert, and D. Hunter, “Food Security and Climate Change,” Food Secur. Clim. Chang., no. June, 2018, doi: 10.1002/9781119180661.

[17] D. P. Van Vuuren, et al. (2007). "Stabilizing greenhouse gas concentrations at low levels: An assessment of reduction strategies and costs,” Clim. Change, vol. 81, no. 2, pp. 119-159, 2007, doi: 10.1007/s10584-006-9172-9.

[18] Intergovernmental Panel on Climate Change (IPCC). (2018). "Summary for Policymakers. In: Global Warming of $1,5^{\circ}$ C," Intergov. Panel Clim. Chang., pp. 1-24, 2018, [Online]. Available: https://www.ipcc.ch/.

[19] T. R. Society. (2021). “Climate change and global warming: Impacts on crop production,” Genet. Modif. Plants, pp. 283-296, 2021, doi: 10.1016/b978-0-12-818564-3.09991-1.

[20] J. L. Hatfield, et al. (2011). “Climate impacts on agriculture: Implications for crop production,” Agron. J., vol. 103, no. 2, pp. 351-370, 2011, doi: 10.2134/agronj2010.0303.

[21] J. L. Hatfield and J. H. Prueger. (2015). “Temperature extremes: Effect on plant growth and development,” Weather Clim. Extrem., vol. 10, pp. 4-10, 2015, doi: 10.1016/j.wace.2015.08.001.

[22] I. Lowe. (1996). “Greenhouse gas mitigation: Policy options,” Energy Convers. Manag., vol. 37, no. 6-8, pp. 741-746, 1996, doi: 10.1016/0196-8904(95)00249-9.

[23] E. Kistner, O. Kellner, J. Andresen, D. Todey, and L. W. Morton. (2018). "Vulnerability of specialty crops to short-term climatic variability and adaptation strategies in the Midwestern USA,” Clim. Change, vol. 146, no. 1-2, pp. 145-158, 2018, doi: 10.1007/s10584-017-2066-1.

[24] C. L. Authors, et al. (2013). “NCAJan11-2013-publicreviewdraft-chap6-agriculture,” pp. 1-35, 2013, [Online]. Available: papers2://publication/uuid/992FEB90-9075-443F-BCDC-EDD29A1B6F96.

[25] J. E. Doll, B. Petersen, and C. Bode. (2017). "Skeptical but adapting: What Midwestern farmers say about climate change," Weather. Clim. Soc., vol. 9, no. 4, pp. 739-751, 2017, doi: 10.1175/WCAS-D-16-0110.1.

[26] A. B. O. U. T. B. I. G. F. A. C. Ts. (2013). “Climate impacts on production,” pp. 2009-2011, 2013.

[27] O. B. Chijioke, M. Haile, and C. Waschkeit. (2011). "Implication of Climate Change on Crop Yield and Food Accessibility in Sub-Saharan Africa,” ZEF Cent. Res. Dev., pp. 1-31, 2011.

[28] S. P. Dhoubhadel, F. Taheripour, and M. C. Stockton. (2016). “Livestock Demand, Global Land Use Changes, and Induced Greenhouse Gas Emissions,” J. Environ. Prot. (Irvine,. Calif)., vol. 07, no. 07, pp. 985-995, 2016, doi: 10.4236/jep.2016.77087.

[29] CIAT and World Bank. (2017). “Climate-Smart Agriculture in Zambia,” CSA Ctry. Profiles Africa Ser., 2017, [Online]. Available: https://ccafs.cgiar.org/publications/climate-smart-agriculture-zambia.

[30] D. J. Abson, E. D. G. Fraser, and T. G. Benton. (2013). "Landscape diversity and the resilience of agricultural returns: A portfolio analysis of land-use patterns and economic returns from lowland agriculture,” Agric. Food Secur., vol. 2, no. 1, p. 1, 2013, doi: 10.1186/2048-7010-2-2.

[31] S. A. Rahman, M. H. Imam, S. W. Wachira, K. M. Farhana, and B. Torres. (2008). "RESEARCH PAPER LAND USE PATTERNS AND THE SCALE OF ADOPTION OF AGROFORESTRY IN THE RURAL LANDSCAPES OF PADMA FLOODPLAIN IN BANGLADESH,” vol. 18, pp. 193-207, 2008.

[32] J. M. Adams, et al. (2017). "The Landlab v1.0 OverlandFlow component: A Python tool for computing shallow-water flow across watersheds,” Geosci. Model Dev., vol. 10, no. 4, pp. 1645-1663, 2017, doi: 10.5194/gmd-10-1645-2017.

[33] G. E. Stout. (1990). Climate and water, vol. 71, no. 12. 1990.

[34] S. Franzel, P. Cooper, G. L. Denning, and D. Eade, “and Agroforestry Development,” no. 119119.

[35] A. Arslan, N. Mccarthy, L. Lipper, S. Asfaw, A. Cattaneo, and M. Kokwe. (2015). "Climate Smart Agriculture? Assessing the Adaptation Implications in Zambia,” J. Agric. Econ., vol. 66, no. 3, pp. 753-780, 2015, doi: 10.1111/1477-9552.12107.

[36] I. K. Odubote and O. C. Ajayi. (2020). "Scaling Up Climate-Smart Agricultural (CSA) Solutions for Smallholder Cereals and Livestock Farmers in Zambia,” Handb. Clim. Chang. Resil., pp. 1115-1136, 2020, doi: 10.1007/978-3-319-93336-8_109.

[37] O. C. Ajayi, F. Place, F. K. Akinnifesi, and G. W. Sileshi. (2011). “Agricultural success from Africa: The case of fertilizer tree systems in Southern Africa (Malawi, Tanzania, Mozambique, Zambia and Zimbabwe),” Int. J. Agric. Sustain., vol. 9, no. 1, pp. 129-136, 2011, doi: 10.3763/ijas.2010.0554.

[38] K. Calvin, et al. (2021). “Bioenergy for climate change mitigation: Scale and sustainability,” GCB Bioenergy, vol. 13, no. 9, pp. 1346-1371, 2021, doi: 10.1111/gcbb.12863.

[39] G. Fischer, M. M. Shah, and H. T. Van Velthuizen. (2002). “Climate change and agricultural vulnerability,” 2002.

[40] M. Mwangi and S. Kariuki. (2015). "Factors Determining Adoption of New Agricultural Technology by Smallholder Farmers in Developing Countries,” Issn, vol. 6, no. 5, pp. 2222-1700, 2015, [Online]. Available: www.iiste.org. 
[41] E. Edward. (2009). “www.econstor.eu,” 2009.

[42] C. Mwema and W. Crewett. (2019). "Social Networks and Commercialisation of African Indigenous Vegetables in Kenya: A Cragg’s Double Hurdle Approach,” Cogent Econ. Financ., vol. 7, no. 1, 2019, doi: 10.1080/23322039.2019.1642173.

[43] T. Lavers. (2018). "Responding to land-based conflict in Ethiopia: The land rights of Ethnic minorities under federalism,” Afr. Aff. (Lond)., vol. 117, no. 468, pp. 462-484, 2018, doi: 10.1093/afraf/ady010.

[44] A. Krause, et al. "Global consequences of afforestation and bioenergy cultivation on ecosystem service indicators.”

[45] B. C. Ringler, Z. Karelina, and R. Pandya-lorch. (2020). “Energy Water,” pp. 1-9, 2020.

[46] T. T. Deressa, R. M. Hassan, and C. Ringler. (2011). "Perception of and adaptation to climate change by farmers in the Nile basin of Ethiopia,” J. Agric. Sci., vol. 149, no. 1, pp. 23-31, 2011, doi: 10.1017/S0021859610000687. 